\title{
Current Status and Future Scope for Nanomaterials in Drug Delivery
}

\author{
Biswajit Mukherjee, Niladri Shekhar Dey, Ruma Maji, \\ Priyanka Bhowmik, Pranab Jyoti Das and \\ Paramita Paul
}

Additional information is available at the end of the chapter

http://dx.doi.org/10.5772/58450

\section{Introduction}

Nanotechnology is a revolutionary field of micro manufacturing involving physical and chemical changes to produce nano-sized materials. The word "nano" is a Latin word meaning "dwarf". Mathematically a nanometer is equal to one thousand millionth of a meter [1]. A nanomaterial consists of aggregated as well as unbound particles. Nanotechnology in scientific terms is defined as the science which deals with processes that occur at molecular and atomic level or at nanolength size. It involves designing, synthesis and characterization of material structure by controlling the shapes and sizes at nano scale. The conversion of a particle to nano scale size changes the properties of the material such as increase in surface area, dominance of quantum effects often associated with minute sizes, higher surface area to volume ratio etc. and varies material's magnetic, thermal and electrical property. For example, copper which is opaque at macro scale becomes transparent at nano scale. Similarly the properties of gold at nanoscale causes change in melting point from $200^{\circ} \mathrm{C}$ to $1068^{\circ} \mathrm{C}$ and colour changes from yellow to blue to violet along with the change in its catalytic property [2]. Nanoparticles are persistent in nature as well. Functional proteins may be classified as nanoparticles. Some biological system consists of nanoparticles which are devoted to locomotory function. The colours on butterfly's wings are due to light being bounced off nanoscale layers in the structure of the wings. The red and yellow colours seen at sunset are also due to nanoparticles [3]. Super paramagnetic iron oxide less than $50 \mu \mathrm{m}$ are used for imaging of organs. They can be even used for treating complicated brain disorder bio-imaging at nano scale size [9]. 
Indian craftsman and artisan used nanotechnology for designing weapons in early times. The first observation and size measurement of nanoparticle were carried out using an ultra microscope by Richard Zsigmondy in 1902. The term nanotechnology was first time used by a researcher named Norio Taniguchi in University of Tokyo in 1974. In 1980 the inventions of two atoms further advanced the field of Nanotechnology. In 1985 fullerene $\mathrm{C}_{60}$ was discovered by Kroto's and Smalley's research team. In 1991 carbon tubes were discovered by Saumio lijima and by 2000 National Nanotechnology Initiative (NNI), The United States was launched which paved the way for future development in nanotechnology [2].

Nanotechnology may be considered as one of the main propellants for technological, economical change as industrial competeition. Nanotechnology has integrated various disciplines including biomedicine, engineering and technology. Nanotechnology is being used for improving the existing products and to create new products. The strength can be varied accordingly with the requirements of engineering. It can be used to make the water cleaner by remediation to remove its pollutant. It has helped to clean the environment by removing pollutants and has generated cleaner and cheaper energy. It has improved the healthcare system by introducing new devices for diagnosis, monitoring, treatment of diseases and drugdelivery [1].

Nanomaterials have wide applications in pharmaceutical sciences and technology. Few other predominant areas of use of nanotechnology are in drug delivery, and as diagnostic imaging and biosensor. These devices of nanoscale size are popularly known as nanomedicine. Thus nanomedicines are sub-micron size materials $(<1 \mu \mathrm{m})$ which are used for treatment, monitoring and diagnostic purposses. In the present chapter we will discuss on the current status and future strategies of nanosize drug delivery systems.

\section{Significance of nanomaterials in drug delivery}

There are many reasons for which nanoscale size drug delivery systems are attractive to formulation scientists. The most important reason is that number of surface atoms or molecules to the total number of atoms or molecules increases in drug delivery systems. Thus the surface area increases. This helps to bind, adsorb and carry with other compounds such as drug, probes and proteins. The drug particles itself can be engineered to form nanoscale size materials too [4]. The nanosize device systems, sizes smaller than eukaryotic or prokaryotic cells, can eventually much more in amount reach in generally inaccessible areas such as cancer cells, inflamed tissues etc. due to their enhanced permeability and retention effect (EPR) and can impair lymphatic drainage thus that can be used for administration of genes, proteins through the peroral route of administration [5]. They can be used to target the reticuloendothelial cells, thereby facilitating passive targeting of drug to the macrophages of liver and spleen and thus enabling a natural system for treating intracellular infections [6]. The nanomaterials used for the purpose should be soluble, safe and biocompatible as well as bioavailable. They should not occlude blood vessel and less invasive and the toxicity associated with the nanomaterials for drug delivery should be 
very low so that they can be used to target the specific diseased tissue in a safe concentration [7]. They need protecting drug from enzymatic and hydrolytic degradation in the gastrointestinal tract and help in bypassing the "first-pass" metabolism in the liver. They generally remain in the circulation for longer time especially those coated with hydrophilic polymers and hence suitable for enhancing the efficacy of drugs with short half-lives and can be used to monitor drug as sustained release formulation as well as for delivering DNA [8]. The dissolution rate of drug is enhanced, onset of therapeutic action is increased, and the dose is reduced. The premature loss of drug through rapid clearance and metabolism can also be prevented [6]. They also increase retention due to bio-adhesion.

Nanoscale drug delivery systems such as nanoparticles, nanoliposomes, dendrimers, fullerence, nanopores, nanotubes, nanoshells, quantum dots, nanocapsule, nanosphere, nanovaccines, nanocrystals etc. are believed to have potentials to revolutionize drug delivery systems. Further nanomaterials on chips, nano robotics, and magnetic nanoparticles attached to specific antibody, nanosize empty virus capsids and magnetic immunoassay are new dimensions of their use in drug delivery. Thus nanomaterials can be used for strategic development of new drug delivery systems and reformulating existing drugs to enhance the effectiveness, patent protection, patient-compliance, safety of drugs and decreasing the cost of health care [9].

\section{Various nanoscale drug delivery systems}

\subsection{Nanoparticles}

Nanoparticles are submicron-sized polymeric colloidal particles with therapeutic agents of interest encapsulated or dispersed within their polymeric matrix or adsorbed or conjugated onto the surface. Commonly used synthetic polymers to prepare nanoparticles for drug delivery are generally biodegradable [10]. Nanoparticles may also be composed of or transport a variety of substances such as silica, gold or other heavy metals, medicaments, quantum dots, nanocrystals, quantum rods and various contrast agents [11]. Nanoparticle systems offer major improvements in therapeutics through site specificity, their ability to escape from multi-drug resistance and the efficient delivery of an agent. They can be used for active drug targeting attaching ligand such as antibody on their surface (Figure 1).

Solid lipid nanoparticles (SLNs) refer to as lipospheres or solid lipid nanospheres, or particles and are generally solid at human physiological temperature $\left(37^{\circ} \mathrm{C}\right)$ and have a diameter less than $1000 \mathrm{~nm}$ [12]. They can be formed from a range of lipids, including mono-, di- and triglycerides, fatty acids, waxes and combinations there of. SLNs must be stabilized by surfactants to form administrable emulsions. SLNs form a strongly lipophilic matrix into which drugs can be loaded for subsequent release. SLNs have been investigated for the delivery of various cancer treatments like colon cancer, breast cancer [13].

Polymer-based nanoparticles have been extensively investigated as drug nanocarriers. The most widely researched synthetic polymers include polylactide (PLA), poly (D,L-lactide-co- 


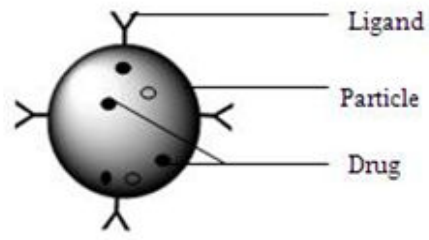

Polymeric nanoparticles with targeting ligands

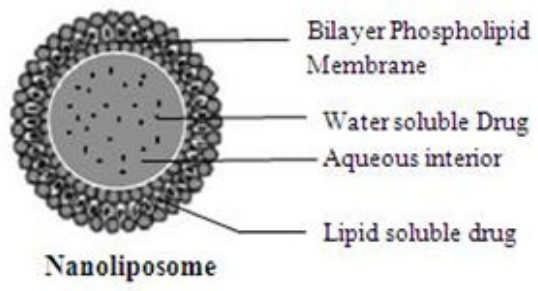

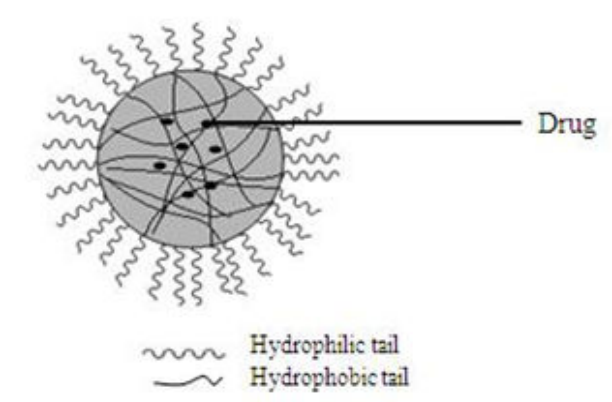

Micelle coated with polyethylene glycol

\section{Dendrimer (three dimensional highly branched polymeric macromolecules)}

Figure 1. Different Types of Nanocarriers for drug delivery

glycolide) (PLGA) and poly ethylene glycol (PEG). All three polymers are hydrolized in vivo and are biodegradable. Other polymers based on biological polysaccharides have been extensively investigated, including chitosan, Clycodextrin and dextrans [14].

Gold nanoparticles (NPs) consist of a core of gold atoms that can be functionalized by addition of a monolayer of moieties containing a thiol (SH) group. Gold NPs can be synthesized using $\mathrm{NaBH}_{4}$ to reduce $\mathrm{AuCL}_{4}{ }^{-}$salts in the presence of thiol containing moieties that subsequently form a monolayer around the core gold atom, depending on the stoichiometric gold/ thiol ratio [15]. Drug delivery using gold NPs has been made in DNA delivery for gene therapy and imaging [16]. PEG coated micelles containing drug are also used to deliver drug as new delivery system (Figure 1). Many other nanoparticulate synthetic, semisynthetic, natural and metals are under investigation to know their potentials as drug delivery materials.

Polymeric nanoparticles may adhere to the cell surface and release drug molecules by diffusion which may enter inside the cell to work. However the entire polymeric nanoparticles can also enter the cell by endocytosis. They bind with the cell surface receptor and formation of endosome takes place. Endosome may be lysed with the help of lysosomal enzymes and the nanoparticles release in the cytoplasm (Figure 2). 


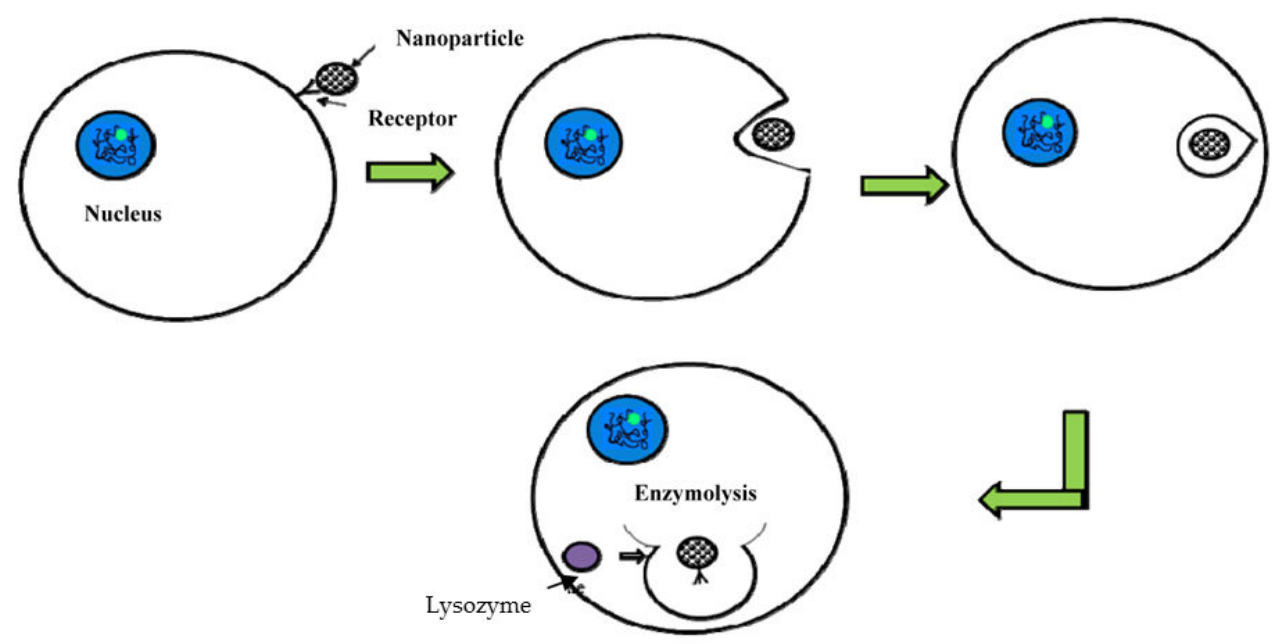

Figure 2. Endocytosis mediated cellular internalization of drug nanocarriers

\subsubsection{Nanoliposomes}

Nanoliposomes are the nanosize vesicles made of bilayered phospholipid membranes generally unilamellar with an aqueous interior (Figure 1) [17]. They can be used for the delivery of low molecular weight drugs, imaging agents, peptides, proteins, and nucleic acids. Different anticancer, antiviral drugs are incorporated within the liposomes [18]. Nanoliposomes can also provide slow release of an encapsulated drug, resulting in sustained exposure to the site of action and enhanced efficacy. Usually hydrophilic drugs can be loaded in aqueous compartment and lipophilic drugs are incorporated in the phospholipid layer [19]. However unlike liposome nanoliposome does not undergo rapid degradation and clearance by liver macrophages. As for the targeted drug delivery, nanoliposome plays an important role. It can be used for passive targeting or active targeting [20]. Due to the leaky vascular structure of the tumor tissue nanoliposomes get predominantly accumulated in the tumor and release the drug for a prolonged period of time in passive targeting. Active targeting is achieved by incorporating antibody, ligands etc. on the nanoliposomal surface. By active targeting liposomes directly go to the targeted organs or tissues, and release drug for a prolonged period of time, so that the normal cells are not affected and only the diseased cells are affected [21]. Targeted nanoliposomal drug delivery is more efficacious than the non-targeted drug delivery systems. C6-ceremide ligand induced nanoliposome used to treat the blood cancer directly targets the over expressed lukemic cells and decreases the high epxpression of survivin protein in leukemic cells [22]. The concept of long-circulating or sterically stabilized nanoliposomes is derived for novelibility of delivery systems which can circulate in the blood for a long period of time. Nanoliposomal formulations containing polyethylene glycol (PEG) alter the pharma- 
cokinetic properties of various drug molecules leading to long elimination half-life [23]. Nanoliposomes are expected to bring lots of change in drug delivery in near future.

\subsubsection{Dendrimers}

Dendrimers are branched polymers, resembling the structure of a tree (Figure 1). Dendrimers represent three dimensional highly branched polymeric macromolecules with the diameter varying from 2.5 to $10 \mathrm{~nm}$. It can be synthesized from both synthetic and natural monomers e.g. aminoacids, monosaccharides and nucleotides. Two classes of dendrimers commonly used for biomedical applications are polyamidoamines and polypropyleneimines [24]. A dendrimer is typically symmetric around the core, and when sufficiently extended it often adopts a spheroidal three-dimensional morphology in water. A central core can be recognized in their structure with at least two identical chemical functionalities. Starting from those groups, repeated units of other molecules can originate with at least one junction of branching. The repetitions of chains and branching result in a series of radially concentric layers with increased crowding [25].

The overall shapes of dendrimers range from spheres to flattened spheroids (disks) to amoebalike structures, especially in cases where surface charges exist and give the macromolecule a "starfish"-like shape. Branching of dendrimers depends on the synthesis processes. Low molecular weight drugs can be placed into the cavities within the dendrimer molecules and are temporarily immobilized there with hydrophobic forces, hydrogen and covalent bonds [26]. The two processes for the synthesis of dendrimers are divergent and convergent methods. In the divergent method dendrimer grows outwords from a multifunctional core molecule. The core molecule reacts with monomer molecules containing one reactive and two dormant groups giving the first generation dendrimer. The convergent method is developed as a response to the weakness of the divergent synthesis. In the convergent approach, the dendrimer is constructed stepwise, starting from the end groups and progressing inwards. When the growing branched polymeric arms, called dendrons, are large enough, they are attached to a multifunctional core molecule. The convergent method is relatively easy to purify the desired product and the occurrence of defects in the final structure is minimised [27]. Due to classical polymerization dendrimers have a negligible degree of polydispersity. They are random in nature and produce molecules of various sizes. The size of dendrimers can be carefully controlled during the process of synthesis of dendrimers. Scientists are focusing on newer approaches for speeding up the synthesis process by preassembly of oligomeric branches which can be linked together to reduce the number of synthesis steps involved and also increase the dendrimer yield [28].

Dendrimers are popularly used for transfer of genetic materials in cancer therapy or other viral diseases in different organs because of their monodisperisity, high density of functional groups, well-defined shape and multivalency. In gene delivery polyamidoamines (PAMAM) dendrimer is widely used. Some other types of dendrimers are peptide dendrimers, glycodendrimers, polypropilimine dendrimers, Polyethyleneimine (PEI) dendrimers etc. 


\subsubsection{Nanoshells}

Nanoshells (100-200 nm) may be used for drug carrier of both imaging and therapy. Nanoshells consist of nanoparticles with a core of silica and a coating of thin metallic shell [29]. They can be targeted to a tissue by using immunological methods. Nanoshells can also be embedded in a hydrogel polymer [30]. Nanoshells are currently being investigated for prevention of micrometastasis of tumors and also for the treatment of diabetes. Nanoshells are useful for diagnostic purposes in whole blood immunoassays [31].

\subsection{Fullerenes and nanotubes}

Fullerenes composed of carbon in the form of a hollow sphere or ellipsoid tube. These are also known as 'bucky balls' because of their resemblance to the geodesic dome design of Buck minster Fuller. Fullerenes are being investigated for drug transport of antiviral drugs, antibiotics and anticancer agents [32]. Fullerenes have the potential to stimulate host immune response and productions of fullerene specific antibodies. Soluble derivatives of fullerenes such as C60 have shown great utility as pharmaceutical agents.

Nanotubes are nanometer scale tube like structure and they are of different types like carbon nanotube, inorganic nanotube, DNA nanotube, membrane nanotube etc. [33]. Carbon nanotubes can be made more soluble by incorporation of carboxylic or ammonium groups to their structures and can be used for the transport of peptides, nucleic acids and other drug molecules. The ability of nanotubes to transport DNA across cell membrane is used in studies involving gene therapy. DNA can be attached to the tips of nanotubes or can be incorporated within the tubes [34].

\subsection{Nanopores}

Nanopores (20 $\mathrm{nm}$ in diameter) consist of wafers with high density of pores which allow entry of oxygen, glucose and other chemicals such as insulin to pass through. Nanopores can be used as devices to protect transplanted tissues from the host immune system, at the same time, utilizing the benefit of transplantation [35]. $\beta$-Cells of pancreas can be enclosed within the nanopore device and implanted in the recipient's body. Nanopores can also be employed in DNA sequencing. Nanopores are also being developed with an ability to differentiate purines from pyrimidines [36].

\subsection{Quantum dots}

Quantum dots (QD) are tiny semiconductor nanocrystals type of particles generally no larger than 10 nanometers that can be made to fluoresce in different colours when stimulated by light. The biomolecule conjugation of the QD can be modulated to target various biomarkers [37]. They can be tagged with biomolecules and used as highly sensitive probes. QD can also be used for imaging of sentinel node in cancer patients for tumour staging and planning of therapy. This technology also outlines some early success in the detection and treatment of breast cancer [38]. QD may provide new insights into understanding the pathophysiology of cancer and real time imaging and screening of tumors. 
Bioconjugated QD are collections of variable sizes of nanoparticles embedded in tiny beads made of polymer material. In a process called "multiplexing," they can be finely tuned to a myriad of luminescent colors that can tag a multitude of different protein biomarkers or genetic sequences in cells or tissues [39]. The new class of quantum dot conjugate contains an amphiphilic triblock copolymer layer for in vivo protection and multiple PEG molecules for improved biocompatibility and circulation, making it highly stable and able to produce bright signals. Another advantage is that quantum dot probes emitting at different wavelengths can be used together for imaging and tracking multiple tumor markers simultaneously, potentially increasing the specificity and sensitivity of cancer detection [40]. Recent progress in the surface chemistry of QD has expanded their use in biological applications, reduced their cytotoxicity and rendered quantum dots a powerful tool for the investigation of dinstinct cellular processes, like uptake, receptor trafficking and intracellular delivery. Another application of QD is for viral diagnosis. Rapid and sensitive diagnosis of Respiratory Syncytial Virus (RSV) is important for infection control and development of antiviral drugs. Antibody-conjugated nanoparticles rapidly and sensitively detect RSV and estimate relative levels of surface protein expression. A major development is the use of dual-colour QD or fluorescence energy transfer nanobeads that can be simultaneously excited with a single light source [41]. QD linked to biological molecules, such as antibodies, have shown promise as a new tool for detecting and quantifying a wide variety of cancer-associated molecules. In the field of nanomedicine, QD can make a worthy contribution to the development of new diagnostic and delivery systems as they offer unique optical properties for highly sensitive detection and they are well defined in size and shape and can be modified with various targeting principles.

\section{Applications of Nanoscale drug delivery systems}

\subsection{Nanotechnology for brain drug delivery}

The blood brain barrier (BBB) is a structure formed by a complex system of endothelial cells, astroglia, pericytes, and perivascular mast cells, preventing the passage of most circulating cells and molecules [42]. The tightness of the BBB is attributed mainly to the vascular layer of brain capillary endothelial cells which are interconnected side-by-side by tight and adherens junctions. Among the different nanodevices, nanosize drug delivery systems between 1 and $100 \mathrm{~nm}$ work as a whole unit in terms of transport to cross BBB [43]. Nanosize brain drug delivery systems may promote the targeting ability of drug in brain and at the same time enhance the permeability of molecules through BBB. However crossing of BBB by the nano drug carriers will depend completely on the physicochemical and biomimetic features and does not depend on the chemical structure of drug, inside the nanoparticles [44]. Nanosize drug carriers which do not cross BBB generally can be made "stealth" coated with some polymeric materials or other chemicals to avoid the reticuloendothelial system, to display long circulation time and stability in blood, and may be functionalized to successfully cross the BBB and target brain [45]. 


\subsection{Nanosize drug carriers in ocular drug delivery}

Drug loaded nanoparticles with favourable biological properties include prolonging the residence time, decreasing toxicity and high ability of drug penetration into the deeper layers of the ocular structure and minimizing precorneal drug loss by the rapid tear fluid turnover [46]. Nanoparticles could target at cornea, retina and choroid by surficial applications and intravitreal injection. Nanocarrier based drug delivery is suitable in the case of the retina, as it has no lymph system, hence retinal neovascularisation and choroidal neovascularization have similar environments to that of solid tumors, and the EPR effect as available for solid nanoparticles in case of solid tumor may be also available for drug delivery targeted to eyes by nanoparticles [47]. Nanoparticles can deliver ocular drugs to the target sites for the treatment of various diseases such as glaucoma, corneal diseases, diabetic retinopathy etc. The uses of nanotechnology based drug delivery systems like nanosuspensions, SLNs and nanoliposomes have greater effect for ocular therapeutic efficacy [48]. Nanotechnology-based drug delivery is also very efficient in crossing membrane barriers, such as the blood retinal barrier in the eye.

\subsection{Nanoparticle loaded contact lenses}

Contact lenses loaded with nanoparticles can be effective for topical administration of ophthalmic drugs. Drug loaded contact lenses can also provide continuous drug release because of slow diffusion of the drug molecules through the lens matrix. The soaked contact lenses also delivered drugs only for a period of few hours for some typical drugs [49]. The duration of drug delivery from contact lenses can be significantly increased if the drug is first entrapped in nanoformulations, such as nanoliposomes, nanoparticles, or microemulsions. Such drug nanocarriers can then be dispersed throughout the contact lens material. The entrapment of drug in nanocarriers also prevents the interaction of drug with the polymerization mixture. This provides additional resistance to drug release, as the drug must first diffuse through the nanocarriers and penetrate the drug carrier surface to reach the contact lens matrix [50].

\subsection{Biodistribution of nanoparticles in the retina}

The ocular biodistribution of nanoparticles can provide insights into the bioavailability, cellular uptake, duration of drug action and toxicity. Factors such as particle size, composition, surface charge and mode of administration influence the biodistribution in the retinal structures and also their drainage from the ocular tissues [51]. Larger particles $(2 \mu \mathrm{m})$ were found to remain in vitreous cavity near the trabecular meshwork from which they are discharged out from the ocular tissue within 6 days, whereas the particles $200 \mathrm{~nm}$ were found evenly distributed in the vitreous cavity, and the inner limiting membrane. The smaller particles $\sim 50 \mathrm{~nm}$ crossed the retinal barriers, and was detected in the retina even after 2 months post injection [52]. The surface chemistry can also affect nanoparticle distribution. Positively charged nanoparticles can adhere to the anionic vitreous network components and aggregate within the vitreous network. The surface chemistry can also affect nanoparticle distribution. Posively charged nanoparticles can adhere to the anionic vitreous network components and aggregate 
within the vitreous humor [53]. Anionic nanoparticles were found to diffuse through the vitreous humor and could even penetrate the retinal layers to be taken up by Muller Cells [54]. Vitreous humor is regarded as the barrier for non-viral ocular gene therapy because of the strong interaction of conventional cationic nature of non-viral gene vectors with the anionic vitreous humor [53]. The cationic PEI nanoparticles aggregated within vitreous humor and were prevented from distributing to the retina by the vitreal barrier. In contrast, cationic glycol chitosan (GC) nanoparticles and GC/PEI blended nanoparticles could penetrate the vitreal barrier and even reach at the inner limiting membrane because of the existence of glycol groups on nanoparticles [55].

\subsection{Nanoparticles in cancer}

Cancer cells are more vulnerable than normal cells to the effect of chemotherapeutic agents and the most of the anticancer drugs can cause injury to the normal cells. Optimum dose and frequency are both important factors in the persistence of cancer cells during cancer chemotherapy [56]. Now attempts are focused on efforts to kill cancer cells by more specific targeting while sparing the normal cells.

Nanoparticulate delivery systems in cancer therapies provide better penetration of therapeutic and diagnostic substances within the cancerous tissue in comparison to conventional cancer therapies [57]. Nanoparticles are constructed to take advantages of fundamental cancer morphology and modes of development such as rapid proliferation of cells, antigen expression, and leaky tumor vasculature. Nanoparticulate drug delivery systems are being developed to deliver smaller doses of chemotherapeutic agents in an effective form and control drug distribution within the body [58]. Nanocarriers can offer many advantages over free drugs in cancer chemotherapy such as they protect the drug from premature degradation, prevent drugs from prematurely interacting with the biological environment, enhance absorption of the drugs into a selected tissue (solid tumour), control the pharmacokinetic and drug tissue distribution profile and improve intracellular penetration [59].

Nanoparticulate delivery systems utilize specific targeting agents for cancer cells minimizing the uptake of the anticancer agent by normal cells and enhance the entry and retention of the agent in tumor cells (Figure 3) [60]. Nanocarriers may actively bind to the specific cancer cells by attaching targeting agents with the help of ligand molecules to the surface of the nanocarriers that bind to specific receptor antigens on the cell surface. Nanocarriers will recognize and bind to target cells through ligand receptor interactions. It is even possible to increase the drug targeting efficacy with the help of antibodies by conjugating a therapeutic agent directly to it for targeted delivery [61].

Like receptor targeting, targeting of angiogenic factors also takes advantage of properties unique to cancer cells. Anti-angiogenic treatment is the use of drugs or other substances to stop tumors from developing new blood vessels. In a study nanoparticles were formulated comprising a water-based core of Vickers microhardness sodium alginate, cellulose sulphate, and anti-angiogenic factors such as thrombospondin (TSP)-1 or TSP-517, crosslinked with dextran polyaldehyde with calcium chloride or conjugated to heparin sulphate with sodium chloride. In addition bioluminescent agent, luciferase, or contrast agent, polymeric gadolinium 
was located within the polyanionic core [62] for drug targeting and detection. Similarly, many efforts are on for cancer cell targeting specifically with drug nanocarriers.. Thus the drug nanocarriers are of great hope for future cancer therapy.

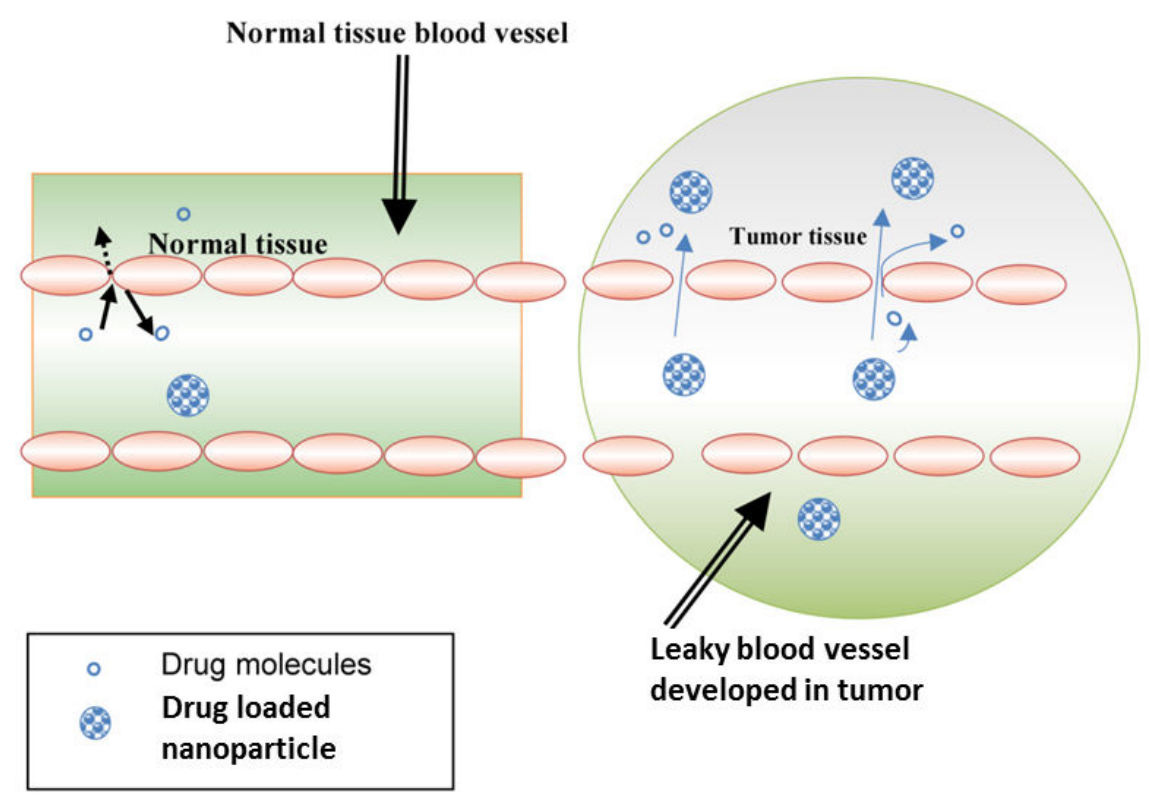

Figure 3. Schematic diagram of nanoparticle permeation and retention effect in normal and tumour tissues. Normal tissue vasculatures are lined by tight endothelial cells, hereby preventing nanoparticulate drug delivery system from escaping, whereas tumor tissue vasculatures are leaky and hyperpermeable allowing preferential accumulation of nanoparticles or nanoliposomes in the tumor interstial space by passive targeting

\subsection{Gene delivery}

Transfer of genetic material in nanocarriers may be an approach for the treatment of various genetic disorders such as diabetes mellitus, cystic fibrosis, alpha 1 antitrypsin deficiency and may more. A number of systemic diseases are caused by lack of enzymes factors that are due to missing or defective genes [63]. Previously gene therapy which was used to treat genetic disorders nowadays being contemplated as carrier systems which could be implanted for combating diseases other than genetic disorder like malignant form of cancer, heart diseases and nervous diseases [64]. Nanoliposomes can be used to deliver genetic materials into cells. Nanoliposomes incorporated with PEG and galactose target liver cells effectively due to their rapid uptake by liver Kupffer cells. Gene therapy may be tried with liposomal nanocarriers for liver disorders such as Wilson's and hereditary hemochromatosis. Cationic nanoliposomes have been considered as potential non-viral human gene delivery system [65]. Another effective method for administering nanoliposomes is by using ligand receptor complex using EGF-EGFR system for targeting purpose by nanoliposomes where EGF is a small protein which 
binds with receptor EGFR. Also mixing cationic lipids with plasmid DNA leads to the formation of lipoplexes where the process is driven by electrostatic interactions [66]. The negatively charged genetic material (e.g. plasmid) is not encapsulated in nanoliposomes but complexed with cationic lipids by electrostatic interactions. Plasmid liposome complexes can enter the disease cells by infusion with the plasma or endosome membrane. Allovectin-7 (gene transfer product) is composed of a plasmid containing the gene for the major histocompatibility complex antigene HLA-B7 with B2 microglobulin formulated with the cytofectin [67]. The nature of a composed lipid decides the unloading of the gene from nanoliposomes which enables control over the mode of release, doping of nanoliposomes with neutral lipids such as 1,2-Dioleoyl-sn-glycero-3-phosphoethanolamine (DOPE) which helps in endosomal membrane fusion by recognizing and destabilizing the phospholipids in a flip flop manner which paves way for the liposomes to integrate in the membrane with the dissociation of nucleic acid into the cytoplasm [64].

Viral system based gene carrier had the ability to overcome the biological barriers in the body and then access to the host nucleus replicative machinery which resulted in the exploitations of the system for drug delivery using nanotechnology [64]. The development of a non-viral method for in vivo gene transfer was designed where the vector was packed into compact nanoparticles by successive additions of oppositely charged polyelectrolytes including an incorporation of ligands into the DNA-polyelectrolyte shells which were mixed with Pluronic F127 gel serving as a biodegradable adhesive to keep shells in contact with the targeted vessel [68].

A novel method of gene delivery is with viruses such as adeno associated virus (AAV) which have their virulent genes removed with lentiviruses, clearly showing their efficiency [64].

\section{Drug delivery with the help of empty virus capsid}

The viral nanoparticles (VNPs) consist of protein core which ranges in complexity from small capsid-protein homomers to larger protein-based heteromers capable of internalizing oligonucleotides and being enveloped by lipids. Chemical modification process and genetic mutation provide the viral coat proteins with receptor binding domain that helps in cell specific targeting of VNPs [69]. Even fusion of terminal / internal proteins on the surface or inside the VNPs can be utilized for introduction of heterologous peptides, and in some cases entire proteins. VNPs can be genetically engineered by inserting amino acids for bioconjugation, peptide based affinity tags and peptides as targeting ligands for stimulation of immune response. [70].

High sequence variability due to the influence of the immune system in viral life-cycles is often seen on the surface loops of viral capsid proteins. This variability makes the loops highly susceptible to insertion of foreign sequences. VP1, the major coat protein of viruses of Polyomaviridae family, when expressed in insect cells, yeast and Escherichia coli self-assembles as protein cages and shows natural affinity for a cell surface glycoprotein with a terminal a 2,3linked N-acetylneuraminic acid and attaches to a4h1-integrin receptors [71]. Virus like particle 
(VLPs) constructed from the virus are used to deliver therapeutic genes to human fetal glial cells. Another technique Cell-docking involves attachment of antibodies to the surface of brain natriuretic peptide (BNPs). Coupling reaction between murine polyoma-virus and antitumor antibody B3 yielded polyoma VLPs with 30 to 40 antibody fragments bound to the surface, allowing the modified VLPs to bind to the breast carcinoma cells with high efficiencies [72].

\section{A glimpse to future of nanosize drug delivery systems}

Advancement of nanosize drug delivery systems establishes a new paradigm in pharmaceutical field. Convergence of science and engineering leads a new era of hope where medicines will act with increase efficacy, high bioavailability and less toxicity. Several nanoscale drug delivery systems are currently in clinical trials and few of them are already commercially available. Examples of such products are Abeicet (for fungal infection), Doxil (antineoplastic), Abraxane (metastatic breast cancer), Emend (antiemetic) etc. Despite the impressive progress in the field, very few nanoformulations have been approved by US-FDA (United States Food and Drug Administration) and even reached market in recent years. Although nanocarriers have lots of advantages because of the unique properties they have, there are many clinical, toxicological and regulatory aspects which are the matters of concern too. The biocompatibility of nanomaterials is of atmost importance because of the effect of the nanomaterials in the body ranging from cytotoxicity to hypersensitivity [8]. With the advancement of nanotechnology, the biological phenomenon such as host response to a specific nanomaterial should also be clinically transparent [9]. Therefore it is quite essential to introduce cost effective, better and safer nanobiomaterials which will provide efficient drug loading and controlled drug release of some challenging drug moieties for which there is no other suitable delivery available yet.

Nanoliposomes are well developed and presently possess the highest amount of clinical trials among other nanomaterials with some formulations currently in the market. This may be due to the fact that other materials have not been investigated for the same duration and are relatively newer in comparison. However polymer based nanomaterial, carbon nanotubes, gold nanoparticles etc. should not be overlooked because of less number of clinical trials [7].

Genexol-PM is an example which was undergone recent clinical trial. This is an amphiphilic diblock co-polymer (PEG-D, L-Lactic acid) that delivers paclitaxel. Clinical trial currently is in phase IV using Genexol-PM for recurrent breast cancer and phase III for breast cancer. Fungal infections associated with acute leukemia and for central line fungal infections, amphotericin B containing nanoliposomes are in phase IV clinical trial. ThermoDox (Doxorubicin loaded nanoliposome) is currently in phase III trials for hepatocellular carcinoma. Similarly Caelyx, a doxorubicin $\mathrm{HCl}$ loaded nanoliposome that is pegylated, is currently in phase IV trials for ovarian neoplasms [7]. Some recent clinical trials are shown in Table 1.

Ligand or antibody conjugated nanoformulation, bifunctional and multifunctional nanoparticles are the newer research approaches through which detection and treatment of cancerous cells can be achieved. Nanomachines are also largely in the research-and-development phase, but some primitive molecular machines have been tested. An example is nanorobot which is 
capable of penetrating the various biological barriers of human body to identify the cancer cells. Thus, nanodrug delivery systems have a leading role to play in nanomedicine in near future.

\begin{tabular}{|c|c|c|c|c|c|c|}
\hline Product name & Delivery material & Phase & Condition & $\begin{array}{c}\text { Therapeutic } \\
\text { Delivered }\end{array}$ & Sponsor & $\begin{array}{c}\text { Clinicaltrials. gov } \\
\text { Identifier }\end{array}$ \\
\hline & Amphilic diblock & & & & Samyang & \\
\hline Genexol-PM & $\begin{array}{l}\text { Copolymer forming } \\
\text { micelle }\end{array}$ & । & Cell lung cancer & Paclitaxel & $\begin{array}{c}\text { Biopharmaceutical } \\
\text { Corp }\end{array}$ & NCT01023347 \\
\hline Docetaxel-PNP & $\begin{array}{c}\text { Polymeric } \\
\text { nanoparticles }\end{array}$ & 1 & $\begin{array}{l}\text { Advanced solid } \\
\text { malignancies }\end{array}$ & Docetaxel & $\begin{array}{c}\text { Samyang } \\
\text { Biopharmaceutical } \\
\text { Corp }\end{array}$ & NCT01103791 \\
\hline CYT-6091 & AuNP & I & $\begin{array}{c}\text { Unspecified adult } \\
\text { solid tumor }\end{array}$ & TNF & $\mathrm{NCl}$ & NCT00356980 \\
\hline $\begin{array}{c}\text { Paclitaxel } \\
\text { poliglumex }\end{array}$ & $\begin{array}{c}\text { Drug Polymer } \\
\text { Conjugate }\end{array}$ & $\|$ & Prostate cancer & Paclitaxel & $\begin{array}{c}\text { OHSU Knight Cancer } \\
\text { Institute }\end{array}$ & NCT00459810 \\
\hline Kogenate FS & PEG-liposome & I & Hemophilia A & $\begin{array}{c}\text { Recombinant } \\
\text { factor VIII }\end{array}$ & Bayer & NCT00629837 \\
\hline $\begin{array}{l}\text { Long-circulating } \\
\text { liposomal } \\
\text { prednisolone } \\
\text { disodium } \\
\text { phosphate }\end{array}$ & Liposome & ॥ & $\begin{array}{c}\text { Rheumatoid } \\
\text { arthritis }\end{array}$ & Prednisolone & Radboud University & NCT00241982 \\
\hline LE-DT & Liposome & II & Pancreatic cancer & Doxetaxel & Insys Therapeutics Inc & NCT01186731 \\
\hline $\begin{array}{c}\text { Cisplatin and } \\
\text { Liposomal } \\
\text { Doxorubicin }\end{array}$ & Liposome & I & Advanced cancer & $\begin{array}{l}\text { Cisplatin and } \\
\text { doxorubicin }\end{array}$ & $\begin{array}{c}\text { M.D. Anderson Cancer } \\
\text { Center }\end{array}$ & r NCT00507962 \\
\hline $\begin{array}{c}\text { Liposomal } \\
\text { doxorubicin } \\
\text { and bevacizumab }\end{array}$ & Liposome & ॥ & Kaposi's sarcoma & $\begin{array}{c}\text { Doxorubicin and } \\
\text { bevacizumab }\end{array}$ & $\mathrm{NCl}$ & NCT00923936 \\
\hline AP5346 & $\begin{array}{l}\text { Drug polymer } \\
\text { conjugate }\end{array}$ & $\begin{array}{c}\text { Not } \\
\text { stated }\end{array}$ & $\begin{array}{l}\text { Head and neck } \\
\text { cancer }\end{array}$ & $\begin{array}{l}\text { AP5346 and } \\
\text { oxaliplatin }\end{array}$ & $\begin{array}{c}\text { University of } \\
\text { California, San } \\
\text { Diego }\end{array}$ & NCT00415298 \\
\hline
\end{tabular}

Abbreviations: PEG-Polyethylene glycol, TNF-Tumor necrosis factor, NCl-National Cancer Institute, AuNP-Gold nanoparticles

Table 1. Recent Nanodrug Carriers in Clinical Trials (Source: Clinicaltrials.gov)

Nanocarriers may lead to a solution to major unsolved medical problems which will aggressively enhance quality of life.

Regulatory aspect: One of the main areas related to the safety aspects of drug-nanocarrier systems is to encourage academic organizations, industry and regulatory governmental agencies to establish convincing testing procedures on the safety aspects of the nanomaterials. 
The global importance of trade for nanomaterials has established new international organizations, such as the International Council on Nanotechnology (ICON), the International Organization for Standardization (Geneva, Switzerland) etc. for sharing responsibilities in this field. In the year 1996 the NNI was established in the United States of America to coordinate governmental multi-agencies such as the Food and Drug Administration (FDA), the Department of Labor through the Occupational Safety and Health Administration (OSHA), the National Institute for Occupational Safety and Health (NIOSH), and the Environmental Protection Agency (EPA), for the development of nanoscience and technology.

\section{Conclusion}

Last few years several new technologies have been developed for the treatment of various diseases. The use of nanotechnology in developing nanocarriers for drug delivery is bringing lots of hope and enthusiasm in the field of drug delivery research. Nanoscale drug delivery devices present some advantages which show higher intracellular uptake than the other conventional form of drug delivery systems. Nanocarriers can be conjugated with a ligand such as antibody to favor a targeted therapeutic approach. The empty virus capsids are also being tried to use for delivering drugs as a new therapeutic strategy. Thus, nanoscale size drug delivery systems may revolutionize the entire drug therapy strategy and bring it to a new height in near future. However, toxicity concerns of the nanosize formulations should not be ignored. Full proof methods should be established to evaluate both the short-term and longterm toxicity analysis of the nanosize drug delivery systems.

\section{Author details}

Biswajit Mukherjee*, Niladri Shekhar Dey, Ruma Maji, Priyanka Bhowmik, Pranab Jyoti Das and Paramita Paul

*Address all correspondence to: biswajit55@yahoo.com

Department of Pharmaceutical Technology, Jadavpur University, Kolkata, India

\section{References}

[1] Ochekpe NA, Olorunfemi PO, Ngwuluka NC. Nanotechnology and drug delivery part 1: background and applications. Trop J Pharm Res. 2009; 8(3): 265-274.

[2] Commission Staff Working Paper. Types and uses of nanomaterials including safety aspects accompanying the communication from the commission to the European 
Parliament, the council and the European and Economic Social Committee on the Second Regulatory Review on Nanomaterials. SWD 2012; 288 Final.

[3] Svenson S, Prud'homme RK. Multifunctional nanoparticles for drug delivery applications. The nanotech revolution in drug delivery. Cientifica Ltd. 2007; 978-1-46142304-1.

[4] Hadjipanayis CG, Machaidze R, Kaluzova M, Wang L, Schuette AJ, Chen H, Wu X, Mao H. EGFRvIII antibody-conjugated iron oxide nanoparticles for magnetic resonance imaging- guided convection-enhanced delivery and targeted therapy of glioblastoma. Cancer Res. 2010; 70(15): 6303- 6312.

[5] Jong WHD, Borm PJA. Drug delivery and nanoparticle applications and hazards. Int J Nanomedicine. 2008; 3(2): 133- 149.

[6] Sahoo SK, Parveen S, Panda JJ. The present and future of nanotechnology in human healthcare. Nanomed Nanotech Biol Med. 2007; 3(1): 20-31.

[7] Webster DM, Sundaram P, Byrne ME. Injectable nanomaterials for drug delivery: carriers, targeting moieties, and therapeutics. Eur J Pharm Biopham. 2013; 84(1): 1-20.

[8] Chakroborty G, Seth N, Sharma V. Nanoparticles and nanotechnology: clinical, toxicological, social, regulatory and other aspects of nanotechnology. JDDT. 2013; 3(4): 138-141.

[9] Couvreur P. Nanoparticles in drug delivery: past, present and future. Adv Drug Delivery Rev. 2013; 65(1): 21-23.

[10] Panyam J, Labhasetwar V. Biodegradable nanoparticles for drug and gene delivery to cells and tissue. Adv Drug Delivery Rev. 2003; 55(3):329-347.

[11] Praetorius NP, Mandal TK. Engineered nanoparticles in cancer therapy. Recent Pat Drug Deliv and Formul. 2007; 1(1): 37-51.

[12] Pardeike J, Hommoss A, Müller RH. Lipid nanoparticles (SLN, NLC) in cosmetic and pharmaceutical dermal products. Int J Pharm. 2009; 366(1-2): 170-184.

[13] Ogawara KI, Un K, Tanaka K, Higaki K, Kimura T. In vivo anti-tumor mal doxorubicin (DOX) in Dox-resistant tumor-bearing mice: involvement of cytotxic effect on vascular endothelial cells. J Cont Rel. 2009; 133(1): 4-10.

[14] Chan JM, Zhang L, Yuet KP, Liao G, Rhee JW, Langer R, Farokhzad OC. PLGA-lecithin-PEG core-shell nanoparticles for controlled drug delivery. Biomaterials. 2009; 30(8): 1627-1634.

[15] Huang X, Jain PK, El-Sayed IH, El-Sayed MA. Gold nanoparticles: interesting optical properties and recent applications in cancer diagnostics and therapy. Nanomedicine. 2007; 2: 681-693. 
[16] Wei XL, Mo ZH, Li B, Wei JM. Disruption of Hep G2 cell adhesion by gold nanoparticle and paclitaxel disclosed by in situ QCM measurement. Colloids Surf B Biointerfaces. 2007; 59: 100-104.

[17] Yousefi A, Esmaeili F, Rahimian S, Atyabi F, Dinarvand R. Preparation and in vitro evaluation of a pegylated nano-liposomal formulation containing docetaxel. Sci Pharm. 2009; 77: 453-464.

[18] Patel S, Bhirde AA, Rusling JF, Chen X, Gutkind JS, Patel V. Nano delivers big: designing molecular missiles for cancer therapeutics. Pharmaceutics. 2011; 3(1): 34-52.

[19] Patel RP, Patel H, Baria AH. Formulation and evaluation of liposomes of ketokonazole. Int J Drug Deliv Technol. 2009; 1(1): 16-23.

[20] Kumar A, Badde S, Kamble R, Pokharkar VB. Development and characterization of liposomal drug delivery system for nimesulide. Int J Pharm Pharm Sci. 2010; 2(4): 87-89.

[21] Arab Tehrany E, Kahn CJ, Baravian C, Maherani B, Belhaj N, Wang X, Linder M. Elaboration and characterization of nanoliposome made of soya, rapeseed and salmon lecithins: application to cell culture. Colloids Surf B Biointerfaces. 2012; 95: 75-81.

[22] Kumar KPS, Bhowmik D, Deb L. Recent trends in liposomes used as novel drug delivery system. J Pharma Innovation. 2012; 1(1): 26-34.

[23] Dadashzadeh S, Vali AM, Rezaie M. The effect of PEG coating on in vitro cytotoxicity and in vivo disposition of topotecan loaded liposomes in rats. Pharmaceutical Nanotechnology. 2008; 353: 251-259.

[24] Dhanikula RS, Hammady T, Hildgen P. On the mechanism and dynamics of uptake and permeation of polyether copolyester dendrimers across an in vitro blood-brain barrier model. J Pharm Sci. 2009; 98(10): 3748-3760.

[25] Albertazzi L, Gherardini L, Brondi M, Sulis Sato S, Bifone A, Pizzorusso T, Ratto GM, Bardi G. In vivo distribution and toxicity of PAMAM dendrimers in the central nervous system depend on their surface chemistry. Mol Pharmacol. 2013; 10(1): 249-260.

[26] Kannan S, Dai H, Navath RS, Balakrishnan B, Jyoti A, Janisse J, Romero R, Kannan RM. Dendrimer-based postnatal therapy for neuroinflammation and cerebral palsy in a rabbit model. Sci Transl Med. 2012; 4(130): 130ra46.

[27] Klajnert B, Bryszewska M. Dendrimers: properties and applications. Acta Bioch Pol. 2001; 48(1): 199-208.

[28] Huang RQ, Qu YH, Ke WL, Zhu JH, Pei YY, Jiang C. Efficient gene delivery targeted to the brain using a transferrin-conjugated polyethylene glycol-modified polyamidoamine dendrimer. Drug Delivery Systems: Advanced Technologies Potentially Applicable in Personalised Treatment. 2007; 21(4): 1117-1125. 
[29] Kherlopian AR, Song T, Duan Q, Neimark MA, Po MJ, Gohagan JK, Laine AF. A review of imaging techniques for systems biology. BMC Syst Biol. 2008; 2: 74.

[30] Lowery AR, Gobin AM, Day ES, Halas NJ, West JL. Immunonano shells for targeted photothermal ablation of tumor cells. Int J Nanomed. 2006; 1(2): 149-154.

[31] Hirsch LR, Stafford RJ, Bankson JA, Sershen SR, Rivera B, Price RE. Nanosell-mediated near-infrared thermal therapy of tumors under magnetic resonance guidance. Prof Natl Acad Sci USA. 2003; 100: 13549-13554.

[32] Reilly RM. Carbon nanotubes: potential benefits and risks of nanotechnology in nuclear nuclear medicine. J Nucl Med. 2007; 48(7): 1039-1042.

[33] Prato M, Kostarelos K, Bianco A. Functionalized carbon nanotubes in drug design and discovery. Acc Chem Res. 2008; 41(1): 60-68.

[34] Mc Devitt MR, Chattopadhyay D, Kappel BJ, Jaggi JS, Schiffman SR, Antczak C, Njardarson JT, Brentjens R, Scheinberg DA. Tumor targeting with antibody functionalized, radiolabelled carbon nanotubes. J Nucl Med. 2007; 48: 1180-1189.

[35] Freitas RA. Current status of nanomedicine and medical nanorobotics. J Comput Theor Nanosci. 2005; 2: 1-25.

[36] Yadav A, Ghune M, Jain DK. Nanomedicine based drug delivery system. JAPER. 2011; 1(4): 201- 213.

[37] Gangrade SM. Nanocrystals-a way for carrier free drug delivery. Pharma Buzz. 2011; 6: 26-31.

[38] Gao X, Dave SR. Quantum dots for cancer molecular imaging. Adv Exp Med Boil. 2007; 620: 57-73.

[39] Mulder WJM, Koole R, Brandwijk RJ, Storm G, Chin PTK, Strijkers GJ, Donega CM, Nicolay K, Griffioen AW. Quantum dots with a paramagnetic coating as a bimodal molecular imaging probe. Nano letter. 2006; 6: 87-90.

[40] Jain S, Shukla K, Jain V, Saraf S. Nanoparticles: emerging carriers for delivery of bioactive agents. Pharma Times. 2007; 39: 30-35.

[41] Amiot CL, Xu S, Liang S, Pan L, Zhao JX. Near-infrared fluorescent materials for sensing of biological targets. Sensors. 2008; 8(5): 3082-3105.

[42] Petty MA, Lo EH. Junctional complexes of the blood brain barrier: permeability changes in neuroinflammation. Prog Neurobiol. 2002; 68(5): 311-323.

[43] Rabanel JM, Aoun V, Elkin I, Mokhtar M, Hildgen P. Drug loaded nanocarriers: passive targeting and crossing of biological barriers. Curr Med Chem. 2012; 19(19): 3070-3102.

[44] Youns M, Hoheisel JD, Efferth T. Therapeutic and diagnostic applications of nanoparticles. Curr Drug Targets. 2011; 12(3): 357-365. 
[45] Gabathuler R. Approaches to transport therapeutic drugs across the blood- brain barrier to treat brain diseases. Neuro biology of Disease. 2010; 37(1): 48-57.

[46] Kesavan K, Balasubramaniam J, Kant S, Singh PN, Pandit JK. Newer approaches for optimal bioavailability of ocularly delivered drugs: review. Curr Drug Deliv. 2011; 8(2): 172-193.

[47] Yasukawa T. Drug delivery systems for vitreoretinal diseases. Prog Retin Eye Res. 2004; 23(3): 253-281.

[48] Behar-Cohen F. Drug delivery to target the posterior segment of the eye. Med Sci (Paris). 2004; 20(6-7): 701-706.

[49] Gulsen D, Chauhan A. Ophthalmic drug delivery through contact lenses. Invest Ophthalmol Vis Sci. 2004; 45(7): 2342-2347.

[50] Gulsen D, Chauhan A. Dispersion of microemulsion drops in HEMA hydrogel: a potential ophthalmic drug delivery vehicle. Int J Pharm. 2005; 292(1-2): 95-117.

[51] Amrite AC, Edelhauser HF, Singh SR, Kompella UB. Effect of circulation on the and ocular tissue distribution of $20 \mathrm{~nm}$ nanoparticles after periocular administration. Mol Vis. 2008 ; 14: 150-160.

[52] Kim JH, Kim JH, Kim KW, Kim MH, Yu YS. Intravenously administered gold nanoparticles passing through the blood retinal barrier depending on the particle size, and induce no retinal toxicity. Nanotechnology. 2009; 20(50): 505101.

[53] Koo H, Moon H, Han H, Na JH, Huh MS, Park JH, Kwon IC, Kim K, Kim H. The movement of self- assembled amphiphilic polymeric nanoparticles in the vitreous and retina after intravitreal injection. Biomaterials. 2012; 33(12): 3485-3493.

[54] Peeters L, Sanders NN, Braeckmans K, Boussery K, Van de Voorde J, De Smedt SC, Demeester J. Vitreous: a barrier to nonviral ocular gene therapy. Invest Ophthalmol Vis Sci. 2005; 46(10): 3553-3561.

[55] Kim H, Robinson SB, Csaky KG. Investigating the movement of intravitreal human serum albumin nanoparticles in the vitreous and retina. Pharm Res. 2009; 26(2): 329-337.

[56] Surendiran A, Sandhiya S, Pradhan SC, Adithan C. Novel applications of nanotechnology in medicine. Indian J Med Res. 2009; 130: 689-701.

[57] Malam Y, Loizidou M, Seifalian AM. Liposomes and nanoparticles: nanosized vehicles for drug delivery in cancer. Trends Pharmacol Sci. 2009; 30(11): 592-599.

[58] Byrne JD, Betancourt T, Brannon-Peppas L. Active targeting schemes for nanoparticle systems in cancer therapeutics. Adv Drug Delivery Rev. 2008; 60: 1615-1626.

[59] Ruoslahti E, Bhatia SN, Sailor MJ. Targeting of drugs and nanoparticles to tumors. J Cell Biol. 2010; 188 (6): 759-768. 
[60] Praetorius NP, Mandal TK. Engineered nanoparticles in cancer therapy. Recent Pat Drug Deliv Formul. 2007; 1(1): 37-51.

[61] Peer D, Karp JM, Hong S, Farokhzad OC, Margalit R, Langer R. Nanocarriers as an emerging platform for cancer therapy. Nature Nanotech. 2007; 2: 751-760.

[62] Lammers T, Hennink WE, Storm G. Tumour-targeted nanomedicines: principles and practice. British Journal of Cancer. 2008; 99: 392-397.

[63] Davis PB, Cooper MJ. Vectors for airway gene delivery. AAPS J. 2007; 9: E11-E17.

[64] Alex SM, Sharma CP. Nanomedicine for gene therapy. Drug Deliv Transl Res. 2013; 3: $437-445$.

[65] Pathak A, Vyas SP, Gupta KC. Nano-vectors for efficient liver specific gene transfer. Int J Nanomed. 2008; 3: 31-49.

[66] Bunuales M, Duzgunes N, Zalba S, Garrido MJ, Ilarduya CT. Efficient gene delivery by EGF lipoplexes in vitro and in vivo. Nanomedicine. 2011; 6(1): 89-98.

[67] Boettger M, Zaitsev S, Cartier R, Haberland A, Sukhorukov G, Moehwald H, Zastrow H, Schneider M. WO03087384A1 (2003).

[68] Niu L, Xu YC, Dai Z, Tang HQ. Gene therapy for type 1 diabetes mellitus in rats by gastrointestinal administration of chitosan nanoparticles containing human insulin gene. World J Gastroenterol. 2008; 14: 4209-4215.

[69] Caruso M, Belloni L, Sthandier O, Amati P, Garcia MI. Alpha4beta1 integrin acts as a cell receptor for murine polyomavirus at the level. J Virol. 2003; 77: 3913- 3921.

[70] Young M, Willits D, Uchida M, Douglas T. Plant viruses as biotemplates for materials and their use in nanotechnology. Annu Rev Phytopathol. 2008; 46: 361-384.

[71] Gleiter S, Lilie H. Cell-type specific targeting and gene expression using a polyoma VP1 virus-like particles. Biol Chem. 2003; 384(2): 247- 255.

[72] Wang Q, Chan TR, Hilgraf R, Fokin VV, Sharpless KB, Finn MG. Bioconjugation by copper (I)-catalyzed azide-alkyne [3+2] cycloaddition. J Am Chem Soc. 2003; 125(11): 3192 - 3193. 